Research Article

\title{
Application of Chitosan Composite Flocculant in Tap Water Treatment
}

\author{
Awa Kangama ${ }^{(D}$, Defang Zeng $(\mathbb{D}$, Xu Tian, and Jinfu Fang \\ School of Resource and Environmental Engineering, Wuhan University of Technology, 122 Luoshi Road, Wuhan 430070, China \\ Correspondence should be addressed to Defang Zeng; df5152@163.com
}

Received 20 July 2018; Accepted 27 August 2018; Published 21 October 2018

Academic Editor: Wenshan Guo

Copyright ( 2018 Awa Kangama et al. This is an open access article distributed under the Creative Commons Attribution License, which permits unrestricted use, distribution, and reproduction in any medium, provided the original work is properly cited.

The chitosan is a good flocculant for tap water treatment because of its properties such as faster deposition rate and higher removal efficiency for COD (organic matter), SS (suspended solids), and metal ions. However, its high price limits the use in tap water treatment. In this paper, in order to reduce costs, chitosan (CTS), polyaluminum chloride (CF-PAC), and modified rectorite (Al $\left.(\mathrm{OH})_{3}+\mathrm{HCl}\right)$ were combined to prepare the flocculant for tap water treatment. In order to get the optimal composite flocculant formula, first, we combined these flocculants in two-by-two schema and then we combined all the three flocculants together with various dosing amounts. Through comparison between different combination schemas, the best formula of the composite chitosan flocculant was found to be CTS $(\mathrm{ml})$ : CF-PAC $(\mathrm{ml}):$ modified rectorite $\left(\mathrm{Al}(\mathrm{OH})_{3}+\mathrm{HCl}\right)(\mathrm{ml})=1: 30: 5$, with a turbidity removal rate of $96.38 \%$ and a removal rate of aluminum up to $80.1 \%$, while the treatment cost is the lowest. In addition, we have designed a cost-effective method for the treatment cost evaluation. As raw water, we used water from the Han River, which is used as raw water at Zonguan Waterworks. In order to show the effectiveness of our optimal composite chitosan formula, we have compared our treatment results to those of the aluminum polyaluminum chloride flocculant currently used in Zonguan's water treatment plants.

\section{Introduction}

Water is an irreplaceable resource that drives our lives. An adult human should drink 2 to 5 liters of water a day [1-3], and the quality of drinking water is essential for public health. The treatment of drinking water or tap water by flocculation is an important research direction. The flocculation is a solidliquid separation process, which consists of adding a flocculant into the raw water, after which finely divided or dispersed particles are aggregated or agglomerated together to form large particles of such a size (flocs) which settle and cause clarification of the system [4]. According to the literature [5-7], the main flocculants used in tap water treatment are chitosan (CTS) and polyaluminum chloride (PAC). The chitosan is one of the most promising biopolymers for extensive application due to its cationic behaviour. It is a partially deacetylated polymer obtained from the alkaline deacetylation of chitin, a biopolymer extracted from shellfish sources. And it is a linear hydrophilic aminopolysaccharide with a rigid structure containing both glucosamine and acetyl glucosamine units, and each glucosamine unit is composed of a free amino group $\left(-\mathrm{NH}_{2}\right)$. As the active amino groups $\left(-\mathrm{NH}_{2}\right)$ in the chitosan molecule can be protonated with $\mathrm{H}^{+}$in water into a cationic polyelectrolyte [8], chitosan has characteristics of static attraction and adsorption and is widely used in the treatment of wastewater and the elimination of dyes [9]. The chitosan is insoluble in either water or organic solvents but soluble in dilute organic acids such as acetic acid and formic acid and inorganic acids where the free amino groups are protonated and the biopolymer becomes fully soluble $[10,11]$. For more detailed information about the chitosan description, the interested readers can refer to Reference [8]. The flocculation efficiency of the chitosan flocculant in tap water treatment highly depends on its degree of deacetylation (DD) and the molecular weight (MW), which are two very important structural factors for chitosan. In addition, the effects of DD and MW on the final flocculation performance are usually complementary and synergistic [12]. The chemical structures of chitin and chitosan are shown in Figure 1. Compared to traditional chemical flocculants, 


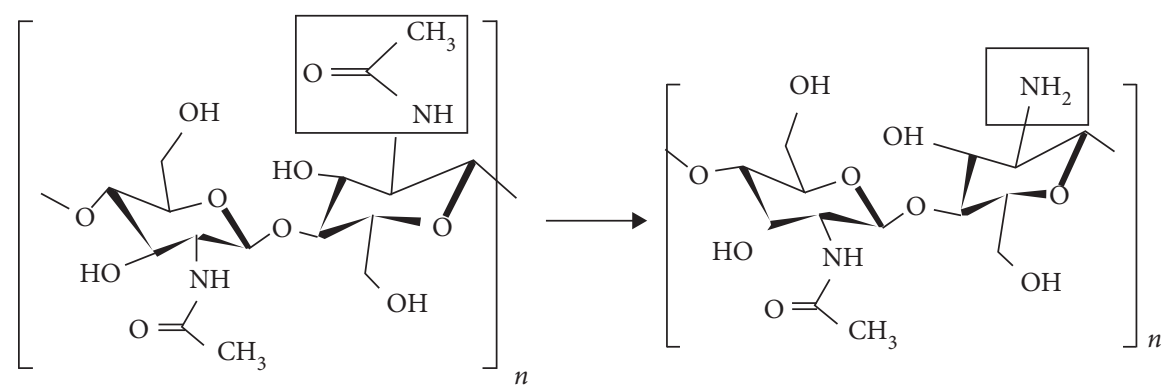

(a)

(b)

Figure 1: Chemical structures of chitin (a) and chitosan (b).

chitosan has a lower dosage, a faster deposition rate, better removal of COD (organic matter) and suspended solids, easier sludge treatment, no pollution, and presence of metal ions amino-D-glucose. However, when we use only the chitosan as a flocculant to treat the tap water, the treatment cost is too high compared to that of traditional chemical flocculants. The unit price of chitosan is much higher than that of traditional chemical flocculants. Therefore, there is a need to prepare a low-cost and efficient composite chitosan flocculant for the tap water treatment. In this paper, we prepare a low-cost and efficient composite chitosan flocculant for the tap water treatment by combining chitosan (CTS), polyaluminum chloride (CF-PAC), and modified rectorite $\left(\mathrm{Al}(\mathrm{OH})_{3}+\right.$ $\mathrm{HCl}$ ).

The remainder of the paper is organized as follows: the experiment method and procedure are presented in Section 2. The experimental results are in detail presented and discussed in Section 3, and Section 4 presents the conclusion.

\section{Experiment}

2.1. Raw Water. In this experiment, raw water from Zonguan Waterworks was used, and raw water from Zonguan Waterworks came from the Han River. The Han River is the largest tributary of the Yangtze River. The choice of the Han River as the source of our water sample is that, in recent years, the pollution of the Han River has increased and the state departments concerned by the various measures to be taken have invested a lot of money to improve the quality of the water from the Han River and got results.

2.2. Main Reagents. Chitosan (CTS) with a mass concentration of chitosan $0.5 \%$ diluted 5 times, polyaluminum chloride (CF-PAC) with a mass concentration of chitosan $2 \%$, and modified rectorite $\left(\mathrm{Al}(\mathrm{OH})_{3}+\mathrm{HCl}\right)$ diluted 5 times are used.

2.3. Main Equipments. MY3000-6 combination mixer (Qianjiang Meiyu Instrument Co., Ltd.) was used to fully control time and stirring speed. Turbidity was measured by using the automatic turbidimeter (2100 PTURBIMETER $\mathrm{HACH}$ ), electronic scale, $100 \mathrm{ml}$ volumetric flask, pipette, beaker, and so on. The flocculant solution was added dropwise with a dropper.
2.4. Experimental Methods and Procedures. We used the water sample by measuring its initial value. With a pipette, $1 \mathrm{~L}$ of water was taken from the water sample, by adding a flocculant to it and stirring it rapidly (200 stirs for 1 minute). After that, stir slowly (90 stirs for 6 minutes first and then 50 stirs for 8 minutes), stop the precipitation for 10 minutes, and then measure its turbidity. The experiment of flocculation and coagulation was performed using MY3000-6. The turbidity is determined by an automatic turbidimeter (2100 PTURBIMETER HACH). The flocculant solution was added dropwise with a dropper. In our experiments, the used degree of deacetylation of chitosan is $88 \%$ and the used molecular weight of chitosan is 500000 .

\section{Results and Discussion}

3.1. Experimental Results of Tap Water Treatment with Simple Flocculants: Chitosan, Polyaluminum Chloride, and Modified Rectorite. As it can be seen from Figure 2, when different quantities of chitosan are added to the raw water, the turbidity of the treated water is between 7 and 9. According to the requirements of the current tap water treatment process, the turbidity of the water after flocculation and sedimentation should be less than 5 NTU before filtering in order to make the final effluent turbidity below 1 NTU. That is, if only chitosan is used to treat the source water of tap water, the treatment effect is not ideal, and also if the used quantity of chitosan is 3 drops per liter of water, the cost is 0.0162 yuan per ton of water, which is nearly $44.6 \%$ higher than the cost of flocculation used at Zonguan Waterworks, 0.0112 yuan per ton of water. Therefore, to sum up in one sentence, the only use of chitosan to treat the source water of tap water cannot reduce costs and improve the treatment effect. Therefore, in this work, we decided to use the composite flocculant composed of polyaluminum chloride, modified rectorite, and chitosan to deal with the treatment of raw water of tap water. The specific circumstances can be found below.

In Figure 3, it can be seen that, with the gradually increasing dosage of polyaluminum chloride, the turbidity of tap water gradually reduces; however, there is not a linear relationship between the amount of polyaluminum chloride and treatment effect. From the treatment effect point of view, it is much better than the chitosan, and tap water turbidity is 


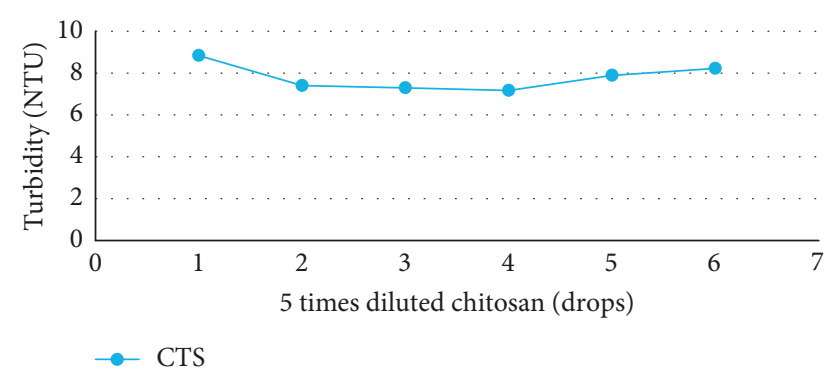

FIgURE 2: Turbidity of raw water of tap water treated with chitosan.

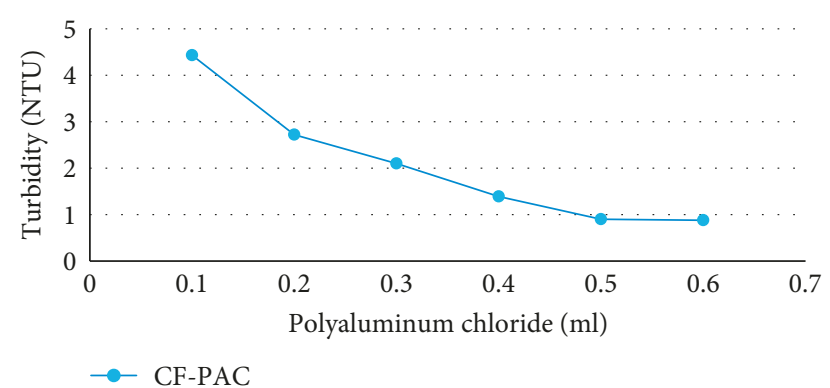

Figure 3: Turbidity of raw water of tap water treated with polyaluminum chloride.

below 5 NTU, but according to Zonguan Waterworks, the added quantity of the flocculant is $20 \mathrm{~kg}$ per ton of water and the percentage of the polyaluminum chloride in $1 \mathrm{~kg}$ of flocculant is $10 \%$; this value exceeds when CF-PAC is added at $0.2 \mathrm{ml}$, which is bound to bring in a large quantity of aluminum, which is not consistent with the goal of reducing the tap water content in aluminum. If the other nonaluminum and nontoxic and harmless flocculants are combined with PAC, the same or better result or effect can be obtained, and also the content of the tap water in aluminum can be reduced.

It can be seen from Figure 4 that, with the increase of the dosage of the modified rectorite, the turbidity of the effluent also decreases, but there is no linear relationship between the dosage and the treatment effect. However, when the dosage is $0.75 \mathrm{ml}$, the treatment effect is better than the best treatment effect of chitosan, and it costs 0.010699 yuan per ton of water. In addition, when the dosage of the modified rectorite is $0.3 \mathrm{ml}$, the effluent turbidity is only $4.98 \mathrm{NTU}$, which is less than $5 \mathrm{NTU}$, and the corresponding cost is also $58.2 \%$ higher than the current cost of flocculation at Zonguan Waterworks.

Based on the above situations (Figures 2-4), the separate use of chitosan, polyaluminum chloride, and modified rectorite in various situations does not have high treatment costs and may cause secondary pollution to tap water. However, if they are combined, it is possible to improve the treatment effect, reduce costs, and reduce or not produce secondary pollution to tap water. Therefore, it is of great value and significance to compound them.

3.2. Experimental Results of Tap Water Treatment with Pair Composite Flocculants from Single Flocculants: Chitosan,

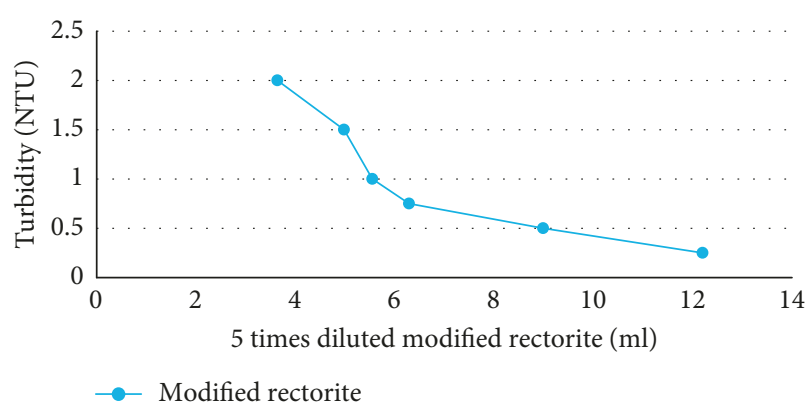

FIGURE 4: Turbidity of raw water of tap water treated with modified rectorite.

Polyaluminum Chloride, and Modified Rectorite. In this section, based on the above experimental data and results, we made the experiments of treating the source water of Zonguan Waterworks by combining chitosan, polyaluminum chloride, and modified rectorite, in two-by-two schema. The specific circumstances of the experiments are as follows.

3.2.1. Cost-Effective Calculation Method. The cost-effective calculation method consists, first, of the calculation of the turbidity removal rate and then the calculation of the cost. To obtain the turbidity removal rate, we subtract the turbidity of the treated effluent from the turbidity of the raw water of the tap water and divide this result by the turbidity of the raw water of the tap water. And by dividing the costs of the treated effluent and the raw water of the tap water by the obtained turbidity removal rate, respectively, we will get a value: the greater this value, the higher the cost ratio of the corresponding formula, and vice versa.

\subsubsection{Flocculation Experiment with Pair Composite Floccu-} lant of Chitosan and Modified Rectorite (CTS + Modified Rectorite). It can be seen from Figure 5 that when the dosage of modified rectorite is $0.25 \mathrm{ml}$ and $0.75 \mathrm{ml}$, the turbidity of the effluent does not decrease gradually with the increase of the dosage of chitosan. When the quantity of added chitosan is 2 drops, the effect becomes worst. While when the quantity of modified rectorite is $1.0 \mathrm{ml}$, the turbidity decreased with the increase of the dosage chitosan.

Using the above cost-effective calculation method with 1 drop of chitosan and $0.25 \mathrm{ml}$ of modified rectorite, we can get the highest cost ratio with a value of 9695.13 . At this time, the cost is 0.008966 yuan per ton of water and the turbidity removal rate is $86.93 \%$. The added amount of chitosan and modified rectorite was 1 drop and $0.50 \mathrm{ml}$, respectively.

\subsubsection{Flocculation Experiment with Pair Composite Floccu-} lant of Chitosan and Polyaluminum Chloride (CTS + PAC). From Figure 6, it can be seen that, with the increase of the dosage of chitosan and polyaluminum chloride, the turbidity of the effluent decreases gradually. When the amount of chitosan and polyaluminum chloride is 3 drops and is $0.4 \mathrm{ml}$, respectively, the best treatment effect is achieved, 


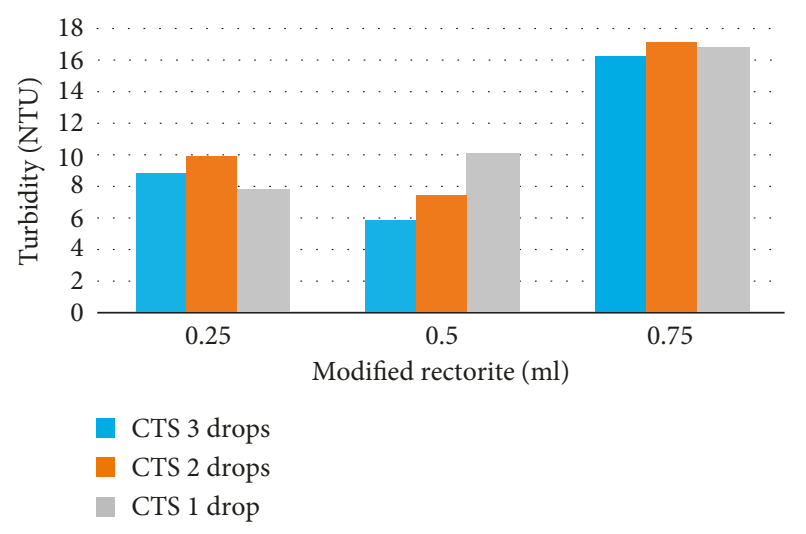

Figure 5: Turbidity of the effluent with chitosan and modified rectorite.

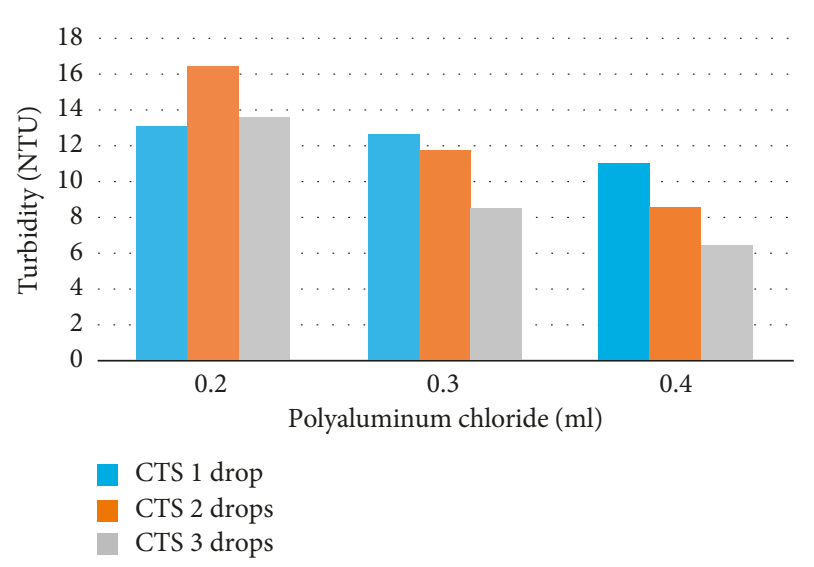

FIgURE 6: The effluent turbidity of raw water with chitosan and polyaluminum chloride.

and the effluent turbidity is $6.52 \mathrm{NTU}$. At this time, the effluent turbidity has not reached the standard below 5 NTU. However, its cost has reached 0.0322 yuan per ton of water. Continuing to increase the dosage of chitosan and polyaluminum chloride is of no practical significance; however, according to the abovementioned cost-effective calculation method, we can get some of the best costeffective formulas. Through the calculation, when the added amount of chitosan and polyaluminum chloride is 1 drop and $0.2 \mathrm{ml}$, respectively, the cost performance ratio is the highest, its value is 6964.93 , the cost is 0.016099 yuan per ton of water, and the turbidity removal rate is $93.33 \%$. While in the added amount of 1 drop of chitosan and $0.3 \mathrm{ml}$ of polyaluminum chloride, the cost is 0.0174 yuan per ton of water.

\subsubsection{Flocculation Experiment with Pair Composite Floccu-} lant of Polyaluminum Chloride and Modified Rectorite (PAC + Modified Rectorite). From Figure 7, it can be seen that when polyaluminum chloride is combined with modified rectorite and the amount of rectorite is constant while the amount of polyaluminum chloride increases, the treatment effect is better; however, the reverse is not the case. When

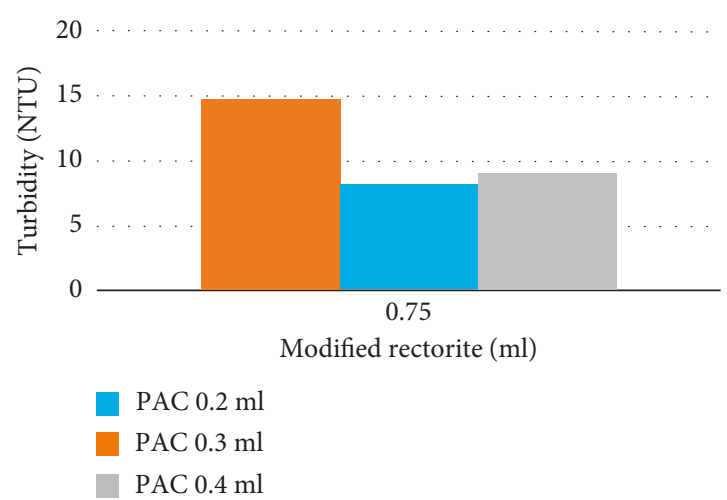

FIgURE 7: Turbidity of water treated with polyaluminum chloride and modified rectorite.

using certain amount of polyaluminum chloride with the added amount of rectorite increasing from $0.50 \mathrm{ml}$ to $0.75 \mathrm{ml}$, the turbidity of the effluent will be increased. According to the above cost-effective method of calculation, when the added amount of polyaluminum chloride and modified rectorite is $0.2 \mathrm{ml}$ and $0.25 \mathrm{ml}$, respectively, the cost performance ratio is the highest, its value is 8066.50 , the cost is 0.011566 yuan per ton of water, and the turbidity removal rate is $93.30 \%$.

\subsection{Experimental Results of Water Treatment with Composite} Flocculation of Chitosan, Polyaluminum Chloride, and Modified Rectorite. In this section, based on the above experimental data and results, we designed experiments of treatment of the raw water of the tap water with the combination of chitosan, polyaluminum chloride, and modified rectorite as the composite flocculant. According to the cost-effective calculation method introduced in Section 3.2.1, we have got several experimental formulas with high cost performance. The following are the specific experimental cases.

From Figure 8, it can be seen that when the dosage of chitosan is 1 drop per liter of raw water, not only the turbidity of the effluent decreases with the increase of polyaluminum chloride and modified rectorite, but also the turbidity of the effluent begins to appear below 5 NTU when the dosage of polyaluminum chloride is $0.2 \mathrm{ml}$ in addition; with the increase of dosage of modified rectorite and polyaluminum chloride, the turbidity of the effluent is getting lower and lower. The turbidity of the effluent reaches the lowest $0.67 \mathrm{NTU}$ when the amount of polyaluminum chloride and modified rectorite is $0.6 \mathrm{ml}$ and $2.0 \mathrm{ml}$, respectively. Therefore, from the experimental results, the effect of the combination of the flocculants is obvious; however, it is expensive if we calculate the cost. According to the cost-effective calculation method, when the added amount of chitosan, polyaluminum chloride, and modified rectorite was 1 drop, $0.10 \mathrm{ml}$, and $0.50 \mathrm{ml}$, respectively, the cost-effective ratio is the highest, its value is 5807.55 , the cost is 0.01653272 yuan per ton of water, and the turbidity removal rate is $96.01 \%$. In addition, when the added amount of chitosan, polyaluminum chloride, and modified rectorite 


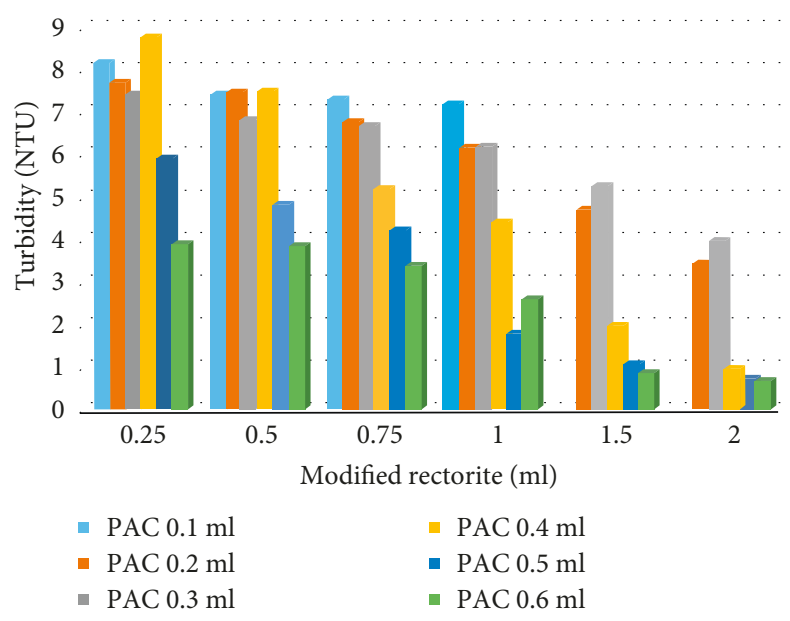

FIGURE 8: Turbidity of tap water treated with 1 drop of chitosan, polyaluminum chloride, and modified rectorite.

was 1 drop, $0.20 \mathrm{ml}$, and $0.25 \mathrm{ml}$, the cost of water treatment is 0.016966 yuan per ton; when the added amount of chitosan, polyaluminum chloride, and modified rectorite was 1 drop, $0.3 \mathrm{ml}$, and $0.25 \mathrm{ml}$, the cost of water treatment is 0.020966 yuan per ton.

As it can be seen in Figure 9, when the added amount of chitosan is 2 drops per liter of the water sample, from the result of the treatment, the effluent turbidity is also the same as that in the case of adding 1 drop of chitosan, and also the effluent turbidity decreases with the increase of the amount of polyaluminum chloride and modified rectorite. However, there is no linear relationship between them, but the greater the added amount of polyaluminum chloride and modified rectorite, the slower the decrease of turbidity of the effluent. With the application of the above cost-effective calculation method, the best formula is 2 drops of chitosan, $0.1 \mathrm{ml}$ of polyaluminum chloride, and $0.25 \mathrm{ml}$ of modified rectorite, the cost performance value is the value of 4957.38, the cost of the treatment of the raw water is 0.018966 yuan per ton of water, and the turbidity removal rate is $94.02 \%$. In the formula, 2 drops of chitosan, $0.1 \mathrm{ml}$ of polyaluminum chloride, and $0.50 \mathrm{ml}$ of modified rectorite, the cost-effective value is 4363.83 , the cost of processing the raw water is 0.021933 yuan per ton of water, and the turbidity removal rate is $95.71 \%$.

3.4. Experimental Results and Discussion of a Formula with High Cost Performance for Each Composite Scheme. Based on the above experimental data and results, the most costeffective formulas were obtained from each composite solution, as shown in Table 1 . The conversion values in Table 1 is obtained by converting the diluted amount of chitosan and modified rectorite into the corresponding amount of $0.5 \%$ chitosan without dilution and modified rectorite without dilution, and then converting the newly obtained $0.5 \%$ chitosan: $2 \%$ polyaluminium chloride: modified rectorite ratio into $\mathrm{ml}$. The value of the example is multiplied by 100 times, and the conversion value in the table is obtained.

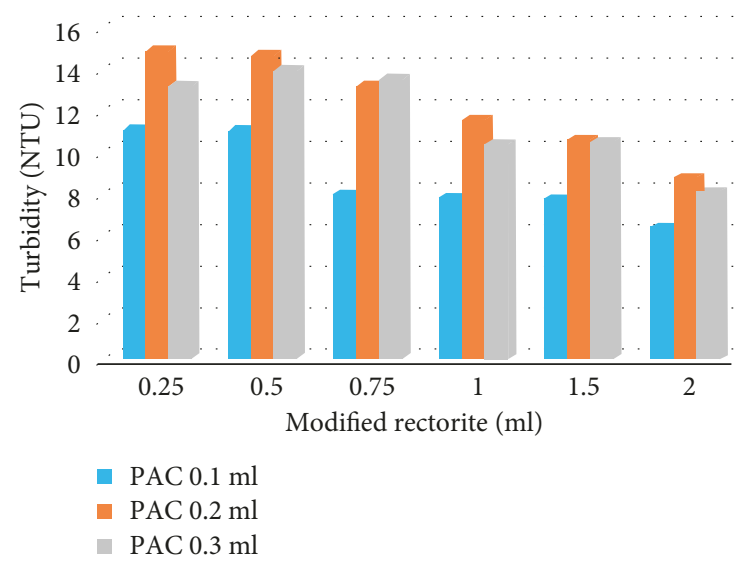

FIgURE 9: Turbidity of the effluent with 2 drops of chitosan, polyaluminum aluminum chloride, and modified rectorite.

3.4.1. The Configuration Method of Each Formula. Each composite scheme formula in Table 1 was converted into its corresponding $0.5 \%$ chitosan: $2 \%$ polyaluminium chloride: double the ratio of modified rectorite. Then the corresponding $0.5 \%$ chitosan, $2 \%$ polyaluminium chloride, and modified rectorite were placed in a $100 \mathrm{ml}$ volumetric flask, which was then filled up to $100 \mathrm{ml}$ with distilled water. The cost of the amount of $1 \mathrm{ml}$ of each formula according to this method is shown in Table 2.

All the reagents used in all the following experiments are the flocculants used in the current production of Zonguan Waterworks. The dosage of the contrast sample flocculant added in the experiment is also in accordance with the dosage of the reagent in general situation of the factory, that is, $20 \mathrm{~kg}$ for thousand tons of water. The specific approach is described as follows: first, with the electronic balance we measure $2.00 \mathrm{~g}$ of flocculant used in the current production of Zonguan waterworks, and then we place this $2.00 \mathrm{~g}$ of flocculant in a $100 \mathrm{ml}$ volumetric flask, which is then filled up to $100 \mathrm{ml}$ with water. Second, we take $1.0 \mathrm{ml}$ of the prepared solution, which contains $0.0200 \mathrm{~g}$ of flocculant. Finally, we add that $1.0 \mathrm{ml}$ of the prepared solution to 1 liter of the source water sample, and this is equivalent to adding $20 \mathrm{~kg}$ of the flocculant into one thousand tons of water tons of source water.

3.4.2. The Experimental Results and Summary of Tap Water Source Water Treatment of Water Source by Each Formula. From Table 3, we can see that when the adding amount in formula no. 1 is $1.6 \mathrm{ml}$, the effluent turbidity is $15.7 \mathrm{NTU}$ which is higher than the turbidity of the comparative sample equal to $10.2 \mathrm{NTU}$, which in turn is obviously larger than 5.5 NTU, apparently in order to achieve the same treatment effect as the comparative sample but also to continue to increase the dosing amount. However, when the dosage (the added amount) of the formula is $1.6 \mathrm{ml}$ per liter, the cost has reached 0.022594 yuan per ton of water, which is more than double the cost of the contrast sample.

From Table 4, it can be seen that when the dosing amount per liter of water in formula no. 2 is $0.8 \mathrm{ml}$ and $0.6 \mathrm{ml}$, the effluent turbidity is $16.1 \mathrm{NTU}$ and 18.1 NTU, respectively, and the water turbidity of the water sample after the contrast sample treatment is $16.48 \mathrm{NTU}$. Therefore, to 
TABLE 1: The correlation of the most cost-effective formulations in each of the composite schemes.

\begin{tabular}{|c|c|c|c|c|}
\hline Number & $\begin{array}{l}\text { CTS (drop) : CF-PAC }(\mathrm{ml}) \text { : modified } \\
\text { rectorite }(\mathrm{ml}) \text { ratio }\end{array}$ & $\begin{array}{l}\text { After conversion, CTS }(\mathrm{ml}) \text { : CF-PAC } \\
(\mathrm{ml}): \text { modified rectorite }(\mathrm{ml}) \text { ratio }\end{array}$ & Turbidity removal rate $(\%)$ & Cost-effective value \\
\hline 1 & $1: 0: 0.5$ & $1: 0: 10$ & 83.25 & 6642.60 \\
\hline 2 & $1: 0.3: 0$ & $1: 30: 0$ & 92.35 & 5307.49 \\
\hline 3 & $1: 0.2: 0$ & $1: 20: 0$ & 93.33 & 6964.93 \\
\hline 4 & $0: 0.2: 0.25$ & $0: 20: 5$ & 93.30 & 8066.50 \\
\hline 5 & $1: 0.1: 0.25$ & $1: 10: 5$ & 75.09 & 5790.87 \\
\hline 6 & $1: 0.2: 0.25$ & $1: 20: 5$ & 96.25 & 5673.04 \\
\hline 7 & $1: 0.3: 0.25$ & $1: 30: 5$ & 96.38 & 4596.97 \\
\hline 8 & $2: 0.1: 0.5$ & $2: 10: 10$ & 95.71 & 4363.83 \\
\hline
\end{tabular}

TABLE 2: Cost of $1 \mathrm{ml}$ solution when each formula is configured into $100 \mathrm{ml}$ solution.

\begin{tabular}{lcccccccc}
\hline Number & 1 & 2 & 3 & 4 & 5 & 6 & 7 & 8 \\
\hline The cost of $1 \mathrm{ml}$ solution & 0.01253 & 0.01740 & 0.01340 & 0.01157 & 0.01270 & 0.01670 & 0.020966 & 0.021933 \\
\hline
\end{tabular}

TABLE 3: Formula no. 1 treatment of tap water source water-related case.

\begin{tabular}{|c|c|c|c|c|c|c|}
\hline \multirow{2}{*}{$\begin{array}{l}\text { Turbidity of raw water } \\
\text { Number }\end{array}$} & \multicolumn{2}{|c|}{$43.9 \mathrm{NTU}$} & \multicolumn{3}{|c|}{ Raw water temperature } & \multirow{2}{*}{$\begin{array}{c}24.5^{\circ} \mathrm{C} \\
\text { Sample of comparison }\end{array}$} \\
\hline & & & 1 & & & \\
\hline Added amount (ml) & 0.8 & 1.0 & 1.2 & 1.4 & 1.6 & 1.0 \\
\hline Water turbidity (NTU) & 18.5 & 18.4 & 17.2 & 15.4 & 15.7 & 10.2 \\
\hline
\end{tabular}

TABLE 4: Formula no. 2 treatment of tap water source water-related case.

\begin{tabular}{|c|c|c|c|c|c|c|}
\hline \multirow{2}{*}{$\begin{array}{l}\text { Turbidity of raw water } \\
\text { Number }\end{array}$} & \multicolumn{2}{|c|}{$65.9 \mathrm{NTU}$} & \multicolumn{3}{|c|}{ Raw water temperature } & \multirow{2}{*}{$\begin{array}{c}24.0^{\circ} \mathrm{C} \\
\text { Sample of comparison }\end{array}$} \\
\hline & & & 2 & & & \\
\hline Added amount (ml) & 0.6 & 0.8 & 1.0 & 1.2 & 1.5 & 1.0 \\
\hline Water turbidity (NTU) & 18.1 & 16.1 & 11.9 & 10.3 & 8.67 & 16.48 \\
\hline
\end{tabular}

achieve a treatment effect close to the contrast sample treatment effect, the dosing amount of the formula should be between 0.6 and $0.8 \mathrm{ml}$ per liter of the sample water, with the corresponding treatment cost of 0.01044-0.01392 yuan per ton of water, which is close to the treatment cost of the contrast sample of 0.0112 yuan per ton of water.

From Table 5, it can be seen that when the dosing amount per liter of water in formula no. 3 is 1.2 and $1.5 \mathrm{ml}$, the effluent turbidity is $22.3 \mathrm{NTU}$ and $15.1 \mathrm{NTU}$, respectively, and the water turbidity of the water sample after the contrast sample treatment is 21.9 NTU. Therefore, to achieve a treatment effect close to the contrast sample treatment effect, the dosing amount of the formula should be between 1.2 and $1.5 \mathrm{ml}$ per liter of the sample water, with the corresponding treatment cost of 0.01608-0.0201 yuan per ton of water, which is much higher than the treatment cost of the contrast sample of 0.0112 yuan per ton of water.

From Table 6, it can be seen that when the dosing amount per liter of water in formula no. 4 is $1.2 \mathrm{ml}$, the effluent turbidity reaches $14.23 \mathrm{NTU}$, which is less than the effluent turbidity of the contrast sample (the comparative effluent turbidity) equal to $14.7 \mathrm{NTU}$, and when the dosing amount is $1.0 \mathrm{ml}$, the effluent turbidity is $15.2 \mathrm{NTU}$, which is slightly larger than 14.7 NTU. Therefore, formula no. 4 can achieve the treatment effect close to the contrast sample treatment effect when the dosing amount is between 1 and
$1.2 \mathrm{ml}$, and the corresponding treatment costs between 0.011566 and 0.0138792 yuan per ton of water, which is higher than the treatment cost of the contrast sample only between 0.0027 and 0.00366 yuan per ton of water.

From Table 7 , it can be seen that when the dosing amount per liter of water in formula no. 5 is $1.0 \mathrm{ml}$ and $1.2 \mathrm{ml}$, the effluent turbidity is $9.93 \mathrm{NTU}$ and $6.03 \mathrm{NTU}$, respectively, while the effluent turbidity of the comparative sample is $8.32 \mathrm{NTU}$. The dosage of $1.0 \mathrm{ml}$ is lower, while the dosage of $1.2 \mathrm{ml}$ is higher, and the corresponding cases are shown in Table 8. It can be concluded that formula no. 5 can achieve the treatment effect close to that of the comparative sample, when the dosing amount is between 1 and $1.2 \mathrm{ml}$ with the corresponding water treatment cost of 0.01270 and 0.01524 yuan per ton of water, which is slightly higher than that of the comparative sample equal to 0.0112 yuan per ton of water.

From Table 8 , it can be seen that when the dosing amount per liter of water in formula no. 6 is 0.8 and $1.0 \mathrm{ml}$, the effluent turbidity is $15.1 \mathrm{NTU}$ and $13 \mathrm{NTU}$, respectively, and the effluent turbidity of the comparative sample is $13.3 \mathrm{NTU}$. Therefore, formula no. 6 can achieve the treatment effect close to that of the contrast sample when the dosing amount per liter of water is between 0.8 and $1.0 \mathrm{ml}$ and closer to $1.0 \mathrm{ml}$, with the corresponding water treatment costs of $0.01357-$ 0.01697 yuan per ton water, which are of $0.00237-0.00577$ 
TABLE 5: Formula no. 3 treatment of tap water source water-related case.

\begin{tabular}{|c|c|c|c|c|c|c|}
\hline \multirow{2}{*}{$\begin{array}{l}\text { Turbidity of raw water } \\
\text { Number }\end{array}$} & \multicolumn{2}{|c|}{$134 \mathrm{NTU}$} & \multicolumn{3}{|c|}{ Raw water temperature } & \multirow{2}{*}{$\begin{array}{c}23.1^{\circ} \mathrm{C} \\
\text { Sample of comparison }\end{array}$} \\
\hline & & & 3 & & & \\
\hline Adding amount (ml) & 0.8 & 1.0 & 1.2 & 1.5 & 2.0 & 1.0 \\
\hline Water turbidity (NTU) & 27.1 & 23.8 & 22.3 & 15.1 & 8.36 & 21.9 \\
\hline
\end{tabular}

TABLE 6: Formula no. 4 treatment of tap water source water-related case.

\begin{tabular}{|c|c|c|c|c|c|c|}
\hline \multirow{2}{*}{$\begin{array}{l}\text { Turbidity of raw water } \\
\text { Number }\end{array}$} & \multicolumn{2}{|c|}{$99.8 \mathrm{NTU}$} & \multicolumn{3}{|c|}{ Raw water temperature } & \multirow{2}{*}{$\begin{array}{c}24.0^{\circ} \mathrm{C} \\
\text { Sample of comparison }\end{array}$} \\
\hline & & & 4 & & & \\
\hline Adding amount (ml) & 0.8 & 1.0 & 1.2 & 1.5 & 2.0 & 1.0 \\
\hline Water turbidity (NTU) & 18.1 & 17.0 & 15.2 & 8.33 & 5.03 & 14.7 \\
\hline
\end{tabular}

TABLE 7: Formula no. 5 treatment of tap water source water-related case.

\begin{tabular}{lcccccc}
\hline $\begin{array}{l}\text { Turbidity of raw water } \\
\text { Number }\end{array}$ & \multicolumn{2}{c}{$23.1 \mathrm{NTU}$} & \multicolumn{2}{c}{ Raw water temperature } & $\begin{array}{c}24.5^{\circ} \mathrm{C} \\
\text { Sample of comparison }\end{array}$ \\
\hline $\begin{array}{l}\text { Adding amount (ml) } \\
\text { Water turbidity (NTU) }\end{array}$ & 0.8 & 1.0 & 1.2 & 1.4 & 1.6 & 1.0 \\
\hline
\end{tabular}

TABLE 8: Formula no. 6 treatment of tap water source water-related case.

\begin{tabular}{|c|c|c|c|c|c|c|}
\hline \multirow{2}{*}{$\begin{array}{l}\text { Turbidity of raw water } \\
\text { Number }\end{array}$} & \multicolumn{2}{|c|}{$99.8 \mathrm{NTU}$} & \multicolumn{3}{|c|}{ Raw water temperature } & \multirow{3}{*}{$\begin{array}{c}24.0^{\circ} \mathrm{C} \\
\text { Sample of comparison } \\
1.0\end{array}$} \\
\hline & & & 6 & & & \\
\hline Adding amount (ml) & 0.6 & 0.8 & 1.0 & 1.2 & 1.5 & \\
\hline Water turbidity (NTU) & 18.5 & 15.1 & 13.0 & 11.4 & 8.07 & 13.3 \\
\hline
\end{tabular}

yuan per ton, respectively, higher than the comparative sample treatment cost of 0.0112 yuan per ton of water.

From Table 9, it can be seen that when the dosing amount per liter of water of formula no. 7 is $0.5 \mathrm{ml}$, the turbidity of the treated sample water is $13.8 \mathrm{NTU}$, which is higher than the effluent turbidity of the contrast sample (the comparative effluent turbidity) equal to $14.3 \mathrm{NTU}$. The water treatment cost of the dosing amount of $0.5 \mathrm{ml}$ is only 0.010483 yuan per ton which is lower (of 0.000717 yuan per ton of water) than the water treatment cost of the comparative sample equal to 0.0112 yuan per ton of water.

From Table 10, it can be seen that when the dosing amount of formula no. 8 is 0.8 and $1.0 \mathrm{ml}$, the turbidity of the treated sample water is 11.6 NTU and 8.22 NTU, respectively, and effluent turbidity of the comparative sample is $11.1 \mathrm{NTU}$. Therefore, in formula no. 8 , to achieve a treatment effect close to that of the comparative sample, the dosing amount of the formula should be between 0.8 and $1.0 \mathrm{ml}$ and closer to $0.8 \mathrm{ml}$, with the corresponding cost of $0.017546-0.02133$ yuan per ton water, which is more than $50 \%$ higher $(0.0063-0101$ yuan per ton of water) than the treatment cost of the comparative sample of 0.0112 yuan per ton of water.

From the comparison between the above 8 formulas and the contrast samples, the effect of formula no. 1, namely, chitosan and modified rectorite composite scheme, is relatively poor, and to achieve the same treatment effect as the comparative sample, the cost will be more than 1 time higher. The chitosan and polyaluminum chloride composite scheme, namely, formula nos. 2 and 3, has a better treatment effect than the chitosan and modified rectorite composite scheme. In particular, formula no. 2 is the exact formula, and the cost of achieving the same treatment effect as the comparative sample is between 0.01044 and 0.01392 yuan per ton of water. The composite solution of polyaluminum chloride and modified rectorite is also better than that of chitosan and modified rectorite. The cost of formula no. 4 is close to 0.112 yuan per ton of water while achieving the same treatment as that of the comparative sample. The combination of chitosan, polyaluminum chloride, and modified rectorite is the best combination of the three. The treatment effect of the application of formula no. 7 to treat the water samples is better than that of the contrast sample when the dosing amount is close to $0.5 \mathrm{ml}$, and the corresponding cost is only 0.010483 yuan per ton of water, which is 0.000717 yuan per ton of water lower than the treatment cost of the comparative sample of 0.0112 yuan per ton of water.

3.5. The Determination of the Best Formula. According to the above summary, three best formula nos. 2, 4, and 7 have been obtained. In order to further determine their performance, they are further compared with the comparative sample. The specific information is shown in Tables 10-12.

Tables 11-13 show formula nos. 2, 4, and 7, configured according to the configuration method described above. The dosing amount of formula no. 2 per liter of the water sample is $0.65 \mathrm{ml}$, whose treatment effect is better than that of the comparative sample. The corresponding treatment 
TABLE 9: Formula no. 7 treatment of tap water source water-related case.

\begin{tabular}{|c|c|c|c|c|c|c|}
\hline \multirow{3}{*}{$\begin{array}{l}\text { Turbidity of raw water } \\
\text { Number } \\
\text { Adding amount }(\mathrm{ml})\end{array}$} & \multicolumn{2}{|c|}{$61.6 \mathrm{NTU}$} & \multicolumn{3}{|c|}{ Raw water temperature } & \multirow{2}{*}{$\begin{array}{c}21.8^{\circ} \mathrm{C} \\
\text { Sample of comparison }\end{array}$} \\
\hline & & & 7 & & & \\
\hline & 0.5 & 0.6 & 0.7 & 0.8 & 1.0 & 1.0 \\
\hline Water turbidity (NTU) & 13.8 & 13.0 & 11.9 & 11.44 & 12.3 & 14.3 \\
\hline
\end{tabular}

TABLE 10: Formula no. 8 treatment of tap water source water-related case.

\begin{tabular}{|c|c|c|c|c|c|c|}
\hline $\begin{array}{l}\text { Turbidity of raw water } \\
\text { Number }\end{array}$ & \multicolumn{2}{|c|}{$123 \mathrm{NTU}$} & \multicolumn{3}{|c|}{ Raw water temperature } & \multirow{2}{*}{$\begin{array}{c}21.8^{\circ} \mathrm{C} \\
\text { Sample of comparison } \\
1.0\end{array}$} \\
\hline Adding amount (ml) & 0.5 & 0.6 & 0.7 & 0.8 & 1.0 & \\
\hline Water turbidity (NTU) & 17.4 & 16.1 & 15.5 & 11.6 & 8.22 & 14.3 \\
\hline
\end{tabular}

Table 11: Comparison experiment of formula nos. 2, 4, and 7 and contrast sample.

\begin{tabular}{|c|c|c|c|c|}
\hline Number & Dosing amount $(\mathrm{ml})$ & Turbidity of treated water (NTU) & Turbidity of raw water & Raw water temperature \\
\hline 4 & 1.1 & 4.45 & \multirow{6}{*}{$75.1 \mathrm{NTU}$} & \multirow{6}{*}{$25.6^{\circ} \mathrm{C}$} \\
\hline 4 & 1.2 & 3.40 & & \\
\hline 2 & 0.8 & 3.38 & & \\
\hline 2 & 0.7 & 5.00 & & \\
\hline 7 & 0.5 & 2.59 & & \\
\hline Comparative sample & 1.0 & 6.14 & & \\
\hline
\end{tabular}

TABle 12: Comparison experiment of formula nos. 2, 4, and 7 and contrast sample.

\begin{tabular}{lcccc}
\hline Number & Dosing amount $(\mathrm{ml})$ & Turbidity of treated water (NTU) & Turbidity of raw water & Raw water temperature \\
\hline 4 & 1.0 & 4.02 & & \\
2 & 0.65 & 6.08 & & \\
2 & 0.6 & 6.38 & & \\
7 & 0.4 & 6.86 & & \\
7 & 0.5 & 3.67 & & \\
Comparative sample & 1.0 & 6.33 & & \\
\hline
\end{tabular}

TABle 13: Comparison experiment of formula nos. 2, 4, and 7 and contrast sample.

\begin{tabular}{lcccc}
\hline Number & Dosing amount $(\mathrm{ml})$ & Turbidity of treated water (NTU) & Turbidity of raw water & Raw water temperature \\
\hline 4 & 1.1 & 22.7 & & \\
4 & 1.2 & 19.2 & $174 \mathrm{NTU}$ & \\
2 & 0.8 & 16.3 & & \\
2 & 0.7 & 16.5 & & \\
7 & 0.4 & 13.3 & & \\
Comparative sample & 1.0 & 23.6 & & \\
\hline
\end{tabular}

cost is 0.01131 yuan per ton of water, which is 0.00011 yuan per ton of water higher than the cost of the contrast sample which is 0.01120 yuan per ton of water. The dosing amount of formula no. 4 per liter of the water sample is $1.0 \mathrm{ml}$, whose treatment effect is better than that of the comparative sample. The corresponding treatment cost is 0.01157 yuan per ton of water, which is only 0.00037 yuan per ton of water higher than the cost of the contrast sample which is 0.01120 yuan per ton of water. And the dosing amount of formula no. 7 per liter of sample water is $0.5 \mathrm{ml}$, whose treatment effect is better than that of the comparative sample. The corresponding treatment cost is 0.01048 yuan per ton of water, which is 0.00072 yuan per ton of water lower than that of the contrast sample. In addition, when the dosing amount of formula no. 2 , no. 4 , and no. 7 is $0.65 \mathrm{ml}, 1.0 \mathrm{ml}$, and $0.5 \mathrm{ml}$, respectively, the treatment effect of formula no. 7 is the best and the corresponding turbidity of effluent is the lowest.

3.6. Comparison of the Effect of Aluminum Removal. In order to show the effectiveness of the solution of formula no. 7 in terms of aluminum removal effect, we treat the raw water of tap water of Zonguan waterworks with the solution of formula no. 7, and we compare the aluminum removal effect of the treated water with that of the flocculant used in Zonguan Waterworks, which is the contrast sample. The used dosing amount of formula no.7 is $0.5 \mathrm{ml}$, and the used dosing amount of the contrast sample is $1.0 \mathrm{ml}$. 
TABLE 14: Aluminum concentration in water after treatment by formula no. 7 of the chitosan composite flocculant and contrast sample.

\begin{tabular}{lcc}
\hline Project & $\begin{array}{c}\text { Aluminum } \\
\text { concentration } \\
(\mathrm{mg} / \mathrm{L})\end{array}$ & $\begin{array}{c}\text { Turbidity } \\
\text { (NTU) }\end{array}$ \\
\hline Raw water & 0.493 & 280 \\
$\begin{array}{l}\text { Effluent after treatment of raw } \\
\text { water with formula no. 7 }\end{array}$ & 0.098 & 4.58 \\
$\begin{array}{l}\text { Effluent after treatment of raw } \\
\text { water with the contrast sample }\end{array}$ & 0.151 & 12.9 \\
\hline
\end{tabular}

As can be seen from Table 14, the use of chitosan compound flocculant no. 7 to treat water supply has a good effect on the removal of aluminum in water, and the removal rate of aluminum is up to $80.1 \%$. The aluminum polyaluminum chloride flocculant used in Zonguan Waterworks now has a removal rate of only $69.4 \%$, which is $10.7 \%$ lower than the optimal formula in this paper. Therefore, the use of the chitosan composite flocculant to treat the tap water raw water can not only improve the effect and reduce the cost but also reduce the content of aluminum ion in the effluent.

\section{Conclusion}

In this work, a low-cost and efficient composite chitosan flocculant for the tap water treatment has been prepared by combining chitosan (CTS), polyaluminum chloride (CF$\mathrm{PAC})$, and modified rectorite $\left(\mathrm{Al}(\mathrm{OH})_{3}+\mathrm{HCl}\right)$. The formula of the prepared composite flocculant is CTS $(\mathrm{ml})$ : CFPAC $(\mathrm{ml})$ : modified rectorite $(\mathrm{ml})=1: 30: 5$. Compared with PAC as the flocculant used at Zonguan Waterworks for tap water treatment, the prepared flocculant has a turbidity removal rate of $96.38 \%$ and a removal rate of aluminum up to $80.1 \%$, while the PAC has a removal rate of aluminum of only $69.4 \%$, which is $10.7 \%$ lower than the optimal formula in this paper. In addition, the treatment cost was also reduced by about 0.0007 yuan per ton of water. The prepared composite chitosan flocculant is of better environmental and economic benefits than the conventional PAC flocculant in tap water treatment. In order to show the effectiveness of our optimal composite formula as the future work, we will apply the optimal composite formula to other tap water raw water.

\section{Data Availability}

The data used to support the findings of this study are included within the supplementary information file.

\section{Conflicts of Interest}

The authors declare that they have no conflicts of interest.

\section{Supplementary Materials}

The supplementary material file contains our experimental data and results. First, we use the single flocculants (chitosan, polyaluminum chloride, and modified rectorite) to treat 1 liter of our sample water and then we measure the turbidity of the treated water. Second, we repeat the experiments using the pair composite flocculant: chitosan and modified rectorite, chitosan and polyaluminum chloride, and polyaluminum chloride and modified rectorite. Finally, we repeat the water treatment experiments by combining chitosan, polyaluminum chloride, and modified rectorite. Through comparison between different combination schemas of three flocculants (Tables 1-14), the best formula of the composite chitosan flocculant was found to be CTS $(\mathrm{ml})$ : CF-PAC $(\mathrm{ml})$ : modified rectorite $\left(\mathrm{Al}(\mathrm{OH})_{3}+\mathrm{HCl}\right)(\mathrm{ml})=1: 30: 5$ with a turbidity removal rate of $96.38 \%$ and a removal rate of aluminum up to $80.1 \%$, while the treatment cost is the lowest. (Supplementary Materials)

\section{References}

[1] G. Howard and J. Bartram, Domestic Water Quantity. Service Level and Health, World Health Organization Document Production Services, Geneva, Switzerland, 2003.

[2] N. Ayni, M. Eben-Chaime, and G. Oron, "Optimizing desalinated sea water blending with other sources to meet magnesium requirements for potable and irrigation waters," Water Research, vol. 47, no. 7, pp. 2164-2167, 2013.

[3] I. Rosborg, B. Nihlgard, and M. Ferrante, "Mineral composition of drinking water and daily uptake," in Drinking Water Minerals and Mineral Balance Importance, Health Significance, Safety Precautions, I. Rosborg, Ed., pp. 25-32, Springer International Publishing, Basel, Switzerland, 2015.

[4] B. R. Sharma, N. C. Dhuldhoya, and U. C. Merchant, "Flocculants-an ecofriendly approach," Journal of Polymers and the Environment, vol. 14, no. 2, pp. 195-202, 2006.

[5] W. Chun Ming, L. Sha, and Y. Huiling, "Composite flocculant preparation and application in manure wastewater treatment," Journal of Residuals Science \& Technology, vol. 14, no. 2, pp. 137-142, 2017.

[6] Z. Defang and Y. Jizu, "Preparation and application of a new composite chitosan flocculant," International Journal of Environment and Pollution, vol. 21, no. 5, pp. 417-424, 2004.

[7] D. Zeng, P. Zhang, and Z. Feng, "Production of chitosan used for flocculant in medium scale," Chinese Journal of Environmental Science, vol. 254-255, no. 1, pp. 62-65, 2002.

[8] C. S. Lee, J. Robinson, and M. F. Chong, "A review on application of flocculants in wastewater treatment," Process Safety and Environmental Protection, vol. 92, no. 6, pp. 489508, 2014.

[9] C. G. Li, F. Wang, W. G. Peng, and Y. H. He, "Preparation of chitosan and epichlorohydrin cross-linked adsorbents and adsorption property of dyes," Applied Mechanics and Materials, vol. 423-426, pp. 584-587, 2013.

[10] F. Renault, B. Sancey, P. M. Badot, and G. Crini, "Chitosan for coagulation/flocculation processes-an eco-friendly approach," European Polymer Journal, vol. 45, no. 5, pp. 13371348, 2009.

[11] A. Szyguła, E. Guibal, M. A. Palacín, M. Ruiz, and A. M. Sastre, "Removal of an anionic dye (Acid Blue 92) by coagulationflocculation using chitosan," Journal of Environmental Management, vol. 90, no. 10, pp. 2979-2986, 2009.

[12] R. Yang, H. Li, M. Huang, Y. Hu, and A. Li, "A review on chitosan-based flocculants and their applications in water treatment," Water Research, vol. 95, pp. 59-89, 2016. 

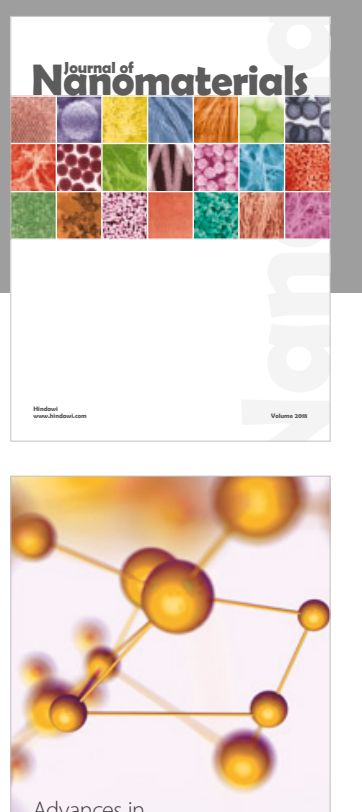

Physical Chemistry
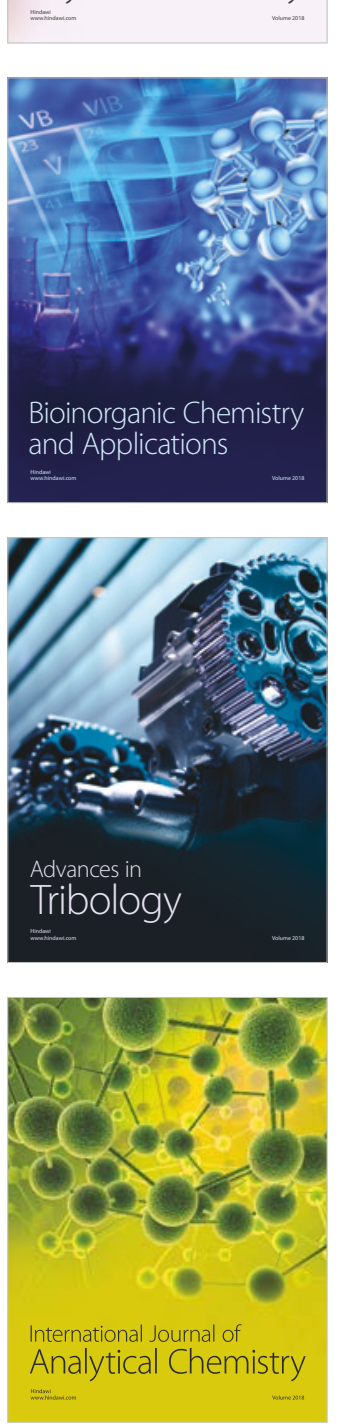

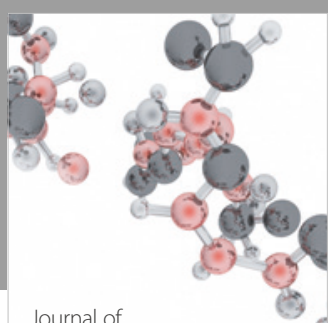

Analytical Methods

in Chemistry

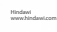

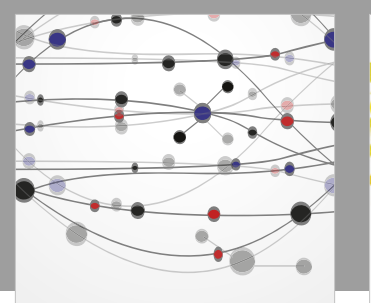

The Scientific World Journal

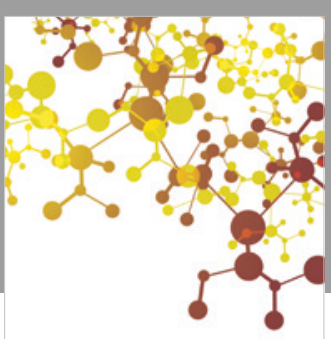

Journal of

Applied Chemistry
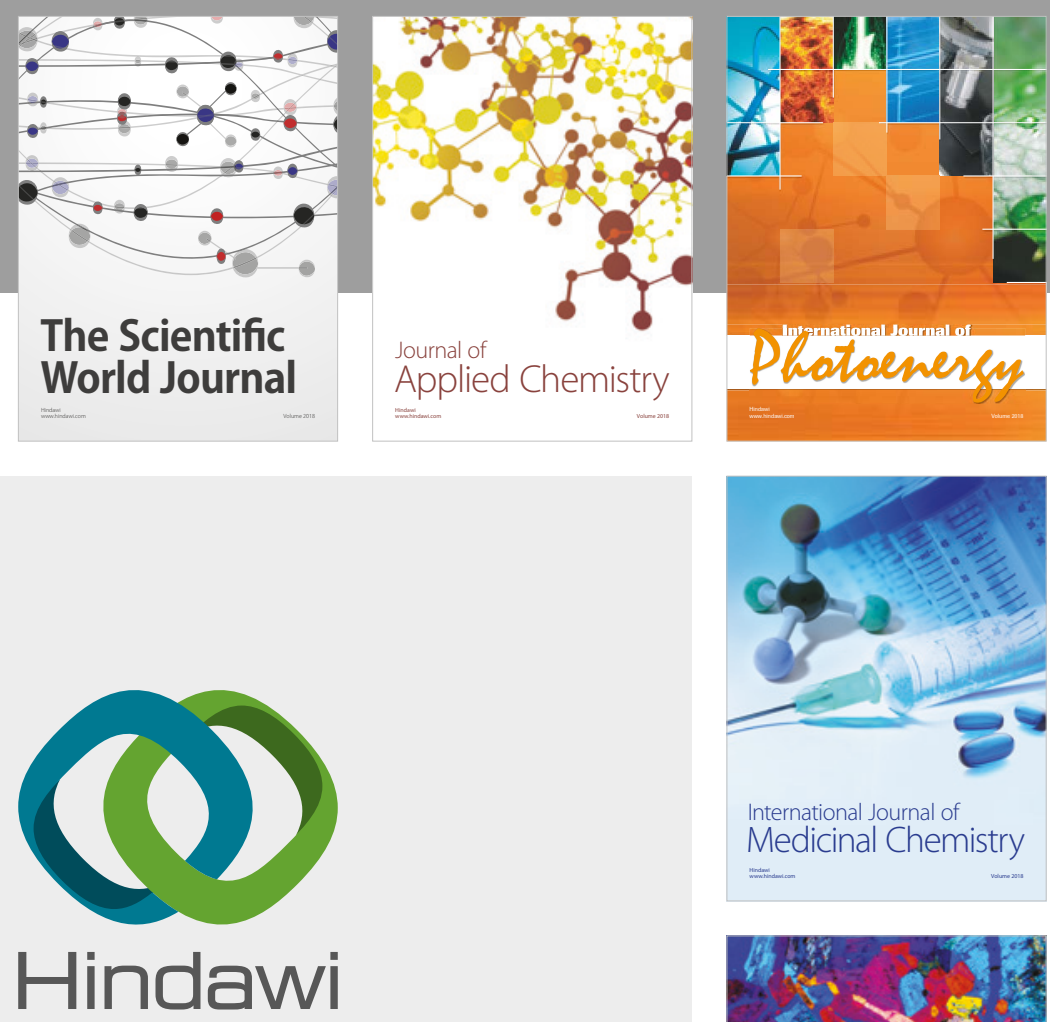

Submit your manuscripts at

www.hindawi.com
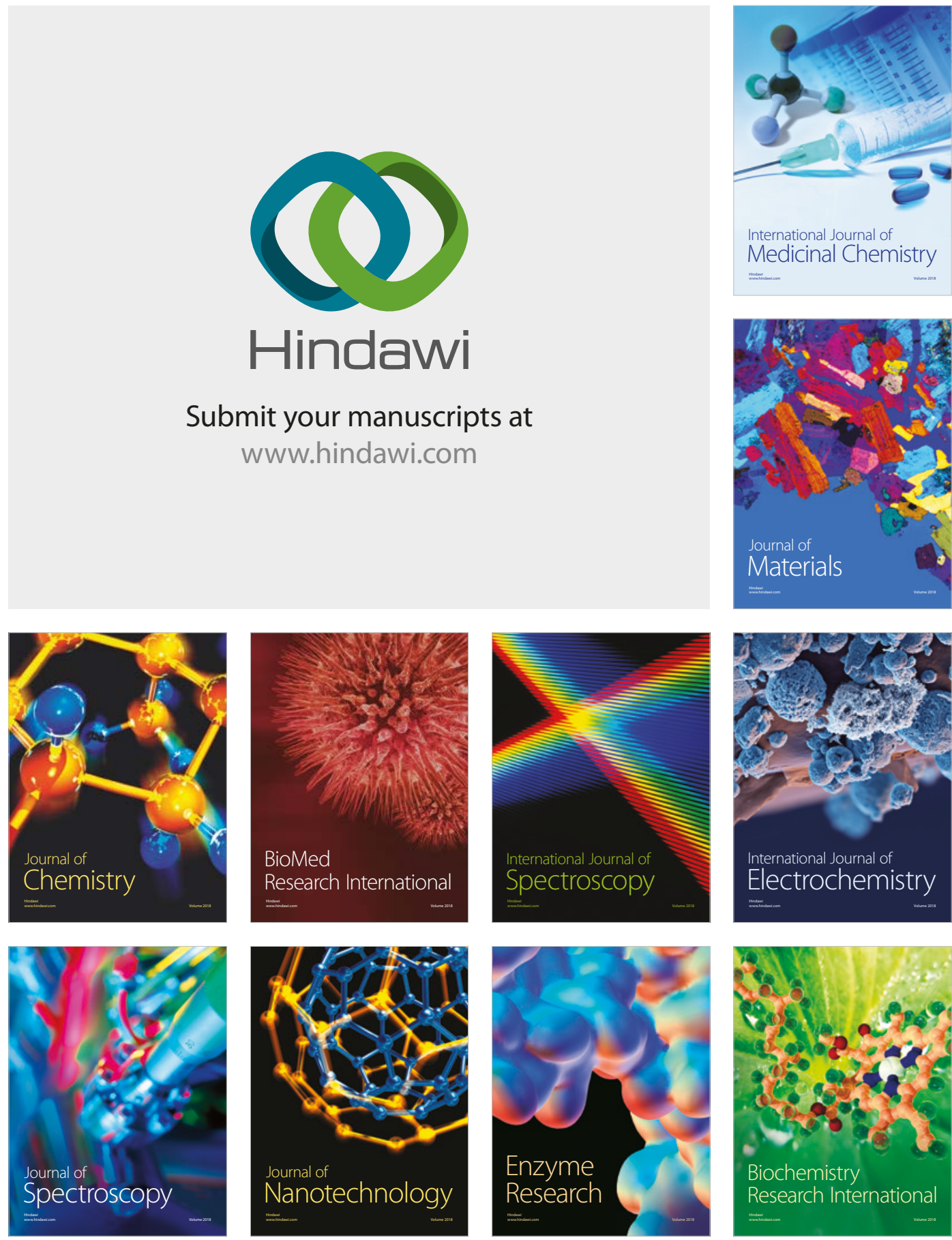
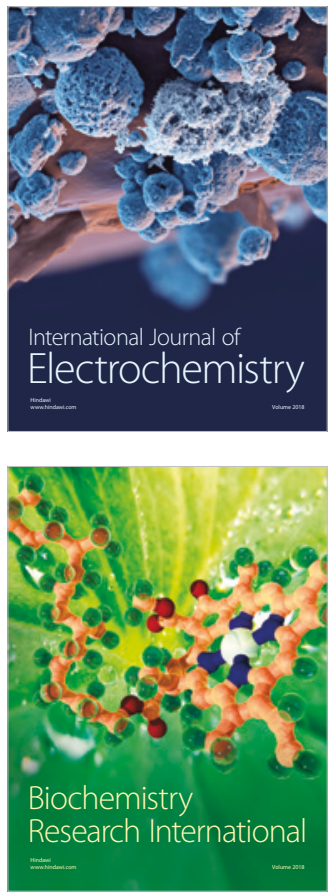